\title{
Enhancing apoptotic cell clearance mitigates bacterial translocation and promotes tissue repair after gut ischemia-reperfusion injury
}

\author{
RONGQIAN WU, WEIFENG DONG, ZHIMIN WANG, ASHA JACOB, TIANPEN CUI and PING WANG \\ Laboratory of Surgical Research, The Feinstein Institute for Medical Research and Department of Surgery, \\ Hofstra North Shore-Long Island Jewish School of Medicine, Manhasset, NY, USA
}

Received April 16, 2012; Accepted June 4, 2012

DOI: $10.3892 / \mathrm{ijmm} .2012 .1044$

\begin{abstract}
A key aspect of intestinal ischemia/reperfusion (I/R) injury is the increased occurrence of apoptotic cell death in the gut. Insufficient clearance of apoptotic cells leads to increased inflammation and impaired tissue repair. Our recent studies have shown that administration of milk fat globule-epidermal growth factor-factor 8 (MFG-E8), a crucial molecule for apoptotic cell clearance, reduces apoptosis and inflammation under various disease conditions. The purpose of this study was to determine whether MFG-E8 reduces bacterial translocation and promotes tissue repair in a mouse model of gut I/R. Gut ischemia was induced by placing a microvascular clip across the superior mesenteric artery for $90 \mathrm{~min}$ in male adult mice. After removing the clip, recombinant murine MFG-E8 (rmMFG-E8) $(0.4 \mu \mathrm{g} / 20 \mathrm{~g} \mathrm{BW})$ or normal saline (Vehicle) was intraperitoneally injected. At $4 \mathrm{~h}$ after reperfusion, apoptosis in the gut was measured by TUNEL staining. The mesenteric lymph node (MLN) complex was homogenized and plated on chocolate agar plates for bacterial culture. Neutrophil infiltration was assessed by examining myeloperoxidase (MPO) activity in the gut. Vascular endothelial growth factor (VEGF) levels in the gut, an indicator of tissue repair, were measured by western blotting. Out results showed that TUNEL-positive staining in the gut increased significantly in gut I/R vehicletreated mice. Treatment with rmMFG-E8 markedly suppressed the number of apoptotic cells. Bacterial translocation to the MLN was minimal in sham mice, but was extensive in gut I/R vehicle-treated mice. rmMFG-E8 treatment significantly
\end{abstract}

Correspondence to: Professor Ping Wang, Laboratory of Surgical Research, The Feinstein Institute for Medical Research and Department of Surgery, Hof stra North Shore-LIJ School of Medicine, 350 Community Drive, Manhasset, NY 11030, USA

E-mail: pwang@nshs.edu

Key words: milk fat globule-epidermal growth factor-factor 8, gut ischemia/reperfusion, apoptosis, bacterial translocation, vascular endothelial growth factor reduced bacterial translocation to the MLN. Similarly, gut I/R induced a significant increase in intestinal MPO activities in vehicle-treated mice. rmMFG-E8 treatment markedly reduced the increase in intestinal MPO activities after gut I/R. Intestinal levels of VEGF decreased significantly at $4 \mathrm{~h}$ after gut I/R. rmMFG-E8 treatment significantly increased intestinal VEGF levels. Thus, enhancing apoptotic cell clearance by rmMFG-E8 mitigates bacterial translocation, inhibits neutrophil infiltration and promotes tissue repair after gut I/R. Enhancing apoptotic cell clearance can be a novel concept in the treatment of gut I/R injury.

\section{Introduction}

Intestinal ischemia is a common clinical problem occurring in many clinical settings such as superior mesenteric artery occlusion, hemorrhagic shock, cardiac insufficiency with associated low flow state, necrotizing enterocolitis, and small bowel transplant. It is associated with significant morbidity and mortality. Interruption of blood supply to a local area causes ischemia which rapidly damages metabolically active tissues. The restoration of blood flow or reperfusion is necessary to maintain cell function and viability, but alone it elicits a cascade of adverse reactions that paradoxically injure tissues. The pathophysiology of ischemia/reperfusion (I/R) injury is complex, involving many biochemical pathways (1-3). Local and systemic inflammatory derangements occur after I/R (4). Damage to the microcirculation triggers a brisk local, then systemic, inflammatory response $(5,6)$. Several mechanisms have been proposed to explain the tissue injury that results from intestinal ischemia. However, little progress has been made in improving the clinical outcome for this devastating disease. The development of novel and effective therapies are imperative in improving patient outcome in gut I/R injury- related conditions.

Studies in gut I/R patients and animals have demonstrated that a key aspect of gut $I / R$ injury is the increased occurrence of apoptotic cell death in the gut (7-9). A large number of studies have shown that excessive apoptosis has pathological consequences on the immune system (10-18). Without proper clearance, apoptotic cells undergo secondary necrosis and have the potential to pose great harm to the host. Milk fat 
globule-epidermal growth factor-factor 8 (MFG-E8), a secretory protein, is a crucial molecule for apoptotic cell clearance (19-21). Our recent studies have shown that the administration of either MFG-E8-containing exosomes or recombinant murine MFG-E8 (rmMFG-E8), reduces apoptosis and inflammation under various disease conditions (22-24). However, it remains unknown whether MFG-E8 ameliorates bacterial translocation and promotes tissue repair after gut I/R. The purpose of this study was to determine whether MFG-E8 reduces bacterial translocation and promotes tissue repair in a mouse model of gut $\mathrm{I} / \mathrm{R}$.

\section{Materials and methods}

Experimental animals. Adult male C57BL/6J mice, purchased from Taconic (Albany, NY), were used in this study. The mice were housed in a temperature-controlled room on a $12 \mathrm{~h}$ light/dark cycle and fed a standard Purina rat chow diet. The mice were fasted for $12 \mathrm{~h}$ prior to the procedure. Animal experimentation was carried out in accordance with the Guide for the Care and Use of Laboratory Animals (Institute of Laboratory Animal Resources). This project was approved by the Institutional Animal Care and Use Committee (IACUC) of the Feinstein Institute for Medical Research.

Experimental model. Ischemia was induced in male C57BL/6J mice (BW, 20-25 g; Taconic) by clamping the superior mesenteric artery (SMA) for 90 min under general anesthesia using isoflurane. At 90 min after SMA, the vascular clamp was released to allow reperfusion. At the beginning of reperfusion mice were resuscitated with a $0.5-\mathrm{ml}$ intraperitoneal (i.p.) injection of saline and were i.p. treated with recombinant murine MFG-E8 (rmMFG-E8; R\&D Systems, Minneapolis, $\mathrm{MN}$ ) at a dose of $0.4 \mathrm{mg} / 20 \mathrm{~g} \mathrm{BW}$ in $0.5 \mathrm{ml}$ normal saline or normal saline (Vehicle). The isoflurane was discontinued after i.p. injection of rmMFG-E8 or saline. Control animals underwent the same operative procedure with the exception of the SMA clamping (Sham). Four hours after reperfusion, animals were anesthetized and blood and small intestinal samples (non-necrotic areas; they were selected based on the color of the small intestine segment) were harvested for various measurements.

Measurement of $M F G-E 8, B c l-2$, poly (ADP-ribose) polymerase-1 (PARP-1), and vascular endothelial growth factor (VEGF) protein levels. MFG-E8, Bcl-2, cleaved PARP-1 and VEGF protein levels in the small intestine were measured by western blot analysis. The band densities were normalized by $\beta$-actin with the use of the Bio-Rad Image System. Briefly, $25 \mu \mathrm{g}$ of protein from gut samples was fractionated on a Bis-Tris gel and transferred to a $0.22-\mu \mathrm{m}$ nitrocellulose membrane. Blots were blocked with 5\% BSA in Tris-buffered saline containing $0.1 \% \mathrm{v} / \mathrm{v}$ Tween-20. The membranes were then incubated overnight at $4^{\circ} \mathrm{C}$ with the primary antibodies as obtained from respective vendors: rabbit anti-mouse MFG-E8 polyclonal antibody $(1: 1,000 ; \mathrm{R} \& \mathrm{D}$ Systems), rabbit anti-Bcl-2 antibody (1:500; Santa Cruz Biotechnology, Inc., Santa Cruz, CA), rabbit anti-cleaved PARP antibody (1:300; Cell Signaling Technology, Inc., Danvers, MA), and rabbit anti-VEGF antibody (1:500; Santa Cruz Biotechnology, Inc.). The blots were then incubated with horseradish peroxidase-linked anti-rabbit immunoglobulin G (1:10,000; Cell Signaling Technology, Inc.) for $1 \mathrm{~h}$ at room temperature. A chemiluminescent peroxidase substrate (ECL; Amersham Biosciences, Piscataway, NJ) was applied according to the manufacturer's instructions, and the membranes were exposed briefly to radiography film.

TUNEL assay. The presence of apoptotic cells in the small intestine was demonstrated using a green fluorescence-tagged terminal deoxynucleotide transferase dUTP nick-end labeling (TUNEL) staining kit (Roche Diagnostics, Indianapolis, IN) counterstained with propidium iodide and examined under a fluorescence microscope. Apoptotic cells appeared as green fluorescence on a red background staining.

Histopathology. Samples of the small intestine were fixed in $10 \%$ formalin and embedded in paraffin. Tissue blocks were sectioned at a thickness of $5 \mu \mathrm{m}$, transferred to glass slides, and stained with hematoxylin and eosin. Morphologic examinations were performed using light microscopy.

Measurement of myeloperoxidase (MPO) activity. MPO activity in the small intestine was determined using the peroxidase-catalyzed reaction. Briefly, tissues were homogenized in $\mathrm{KPO}_{4}$ buffer containing $0.5 \%$ hexadecyl-trimethyl-ammonium bromide $\left(60^{\circ} \mathrm{C}\right.$ for $\left.2 \mathrm{~h}\right)$. After centrifuging, the supernatant was diluted in reaction solution and DOD was measured at $460 \mathrm{~nm}$ to calculate MPO activity.

Bacterial culture. The mesenteric lymph nodes (MLN) and blood samples were collected for bacterial culture. Briefly, the MLN complex was harvested and equal amounts of wet tissues were homogenized and briefly centrifuged to remove gross particulate matters. Serial log dilutions of tissue homogenates or blood samples were applied. Five hundred microliters of each dilution was then plated on chocolate agar plates (Fisher Scientific) and incubated at $37^{\circ} \mathrm{C}$ for $24 \mathrm{~h}$ under aerobic conditions. The colony-forming units (CFU) were counted and the results were expressed as CFU per gram of tissue (MLN) or positive rates (blood).

Statistical analysis. All data are expressed as means \pm SE and compared by the Student's t-test or one-way ANOVA and the Student Newman-Keuls test. Differences in values were considered significant at $\mathrm{P}<0.05$.

\section{Results}

Intestinal levels of $M F G-E 8$ decrease after gut $I / R$. To determine whether MFG-E8 levels are altered after I/R injury, we measured its protein levels in the small intestine $4 \mathrm{~h}$ post reperfusion after $90 \mathrm{~min}$ ischemia. Intestinal levels of MFG-E8 protein decreased by $71 \%$ after gut I/R (Fig. 1).

rmMFG-E8 attenuates intestinal apoptosis after gut $I / R$. The intestinal expression of Bcl-2, an anti-apoptosis protein, was markedly decreased after gut I/R (Fig. 2). Treatment with rmMFG-E8 increased intestinal Bcl-2 levels dramatically, which were similar to those in the sham animals. On the other hand, the expression of PARP-1, an indicator of 


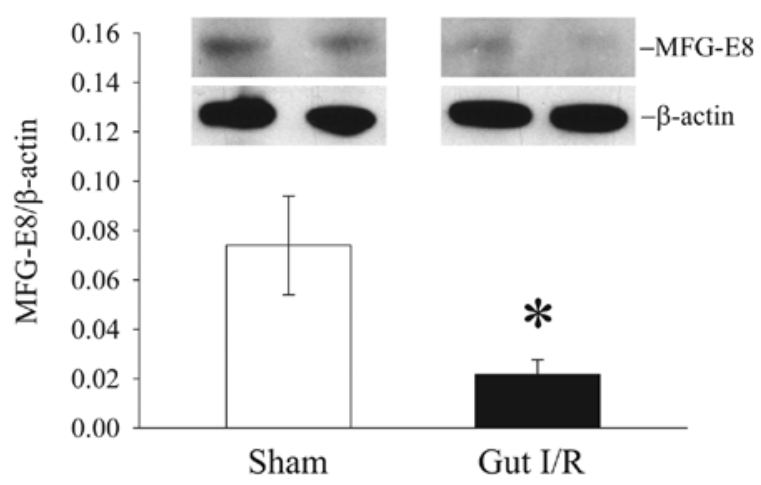

Figure 1. Decrease in intestinal MFG-E8 protein levels after gut I/R. MFG-E8 protein levels were assessed by western blot analysis. A representative gel is presented. Data are expressed as means $\pm \mathrm{SE},{ }^{*} \mathrm{P}<0.05$ vs. Sham by Student's t-test, $\mathrm{n}=5$ /group.

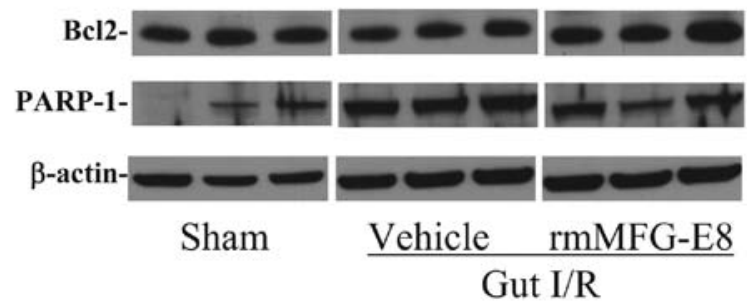

Figure 2. Upregulation of Bcl-2 and downregulation of cleaved PARP-1 by rmMFG-E8 after gut I/R. Small intestinal levels of Bcl-2 and PARP-1 were measured by western blot analysis in sham-operated animals (Sham) and ischemia/reperfusion animals treated with normal saline (Vehicle) or rmMFG-E8 at $4 \mathrm{~h}$ after reperfusion. Representative blots were provided.

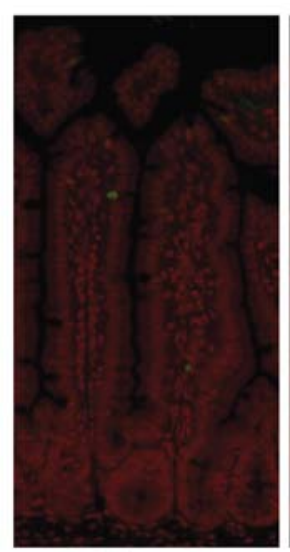

Sham

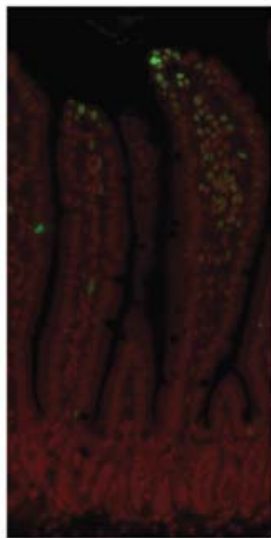

Vehicle

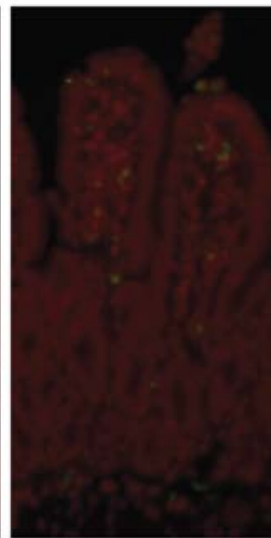

rmMFG-E8

\section{Gut $\mathrm{I} / \mathrm{R}$}

Figure 3. Decreases in apoptosis by rmMFG-E8 after gut I/R. The small intestinal sections were stained with TUNEL (green fluorescence) and counterstained with propidium iodide (red). Photomicrographs of small intestinal sections from sham-operated animals (Sham) and ischemia/reperfusion animals treated with normal saline (Vehicle) or rmMFG-E8 at $4 \mathrm{~h}$ after reperfusion. Original magnification, x100.

apoptosis, increased dramatically at $4 \mathrm{~h}$ after gut I/R (Fig. 2). Administration of rmMFG-E8 reduced intestinal levels of PARP-1 markedly. Consistent with these results, we found an increase in the number of apoptotic cells in the small intestinal

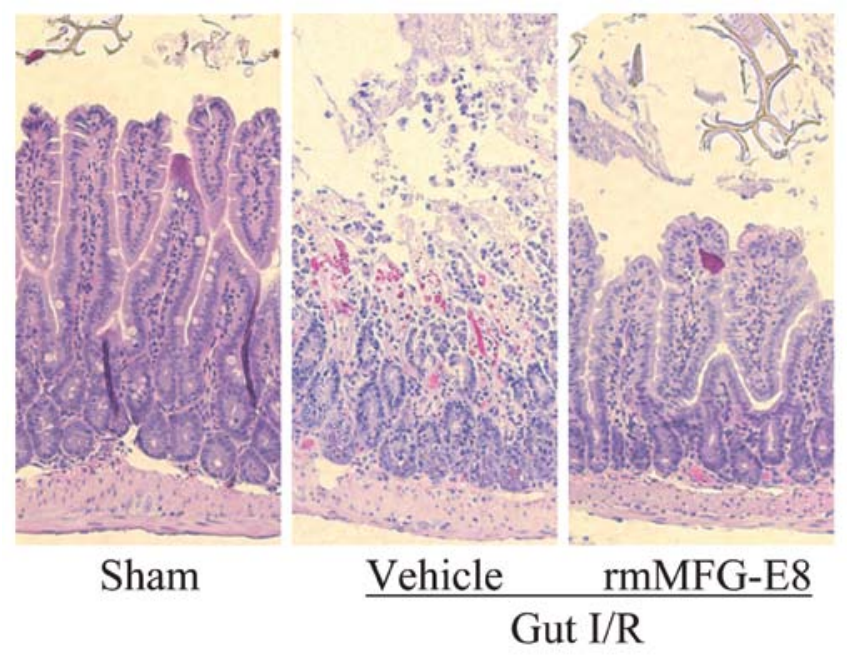

Figure 4. Attenuation of gut injury by rmMFG-E8 after gut I/R. Photomicrographs of small intestinal sections from sham-operated animals (Sham) and ischemia/reperfusion animals treated with normal saline (Vehicle) or rmMFG-E8 at $4 \mathrm{~h}$ after reperfusion. Original magnification, x100.

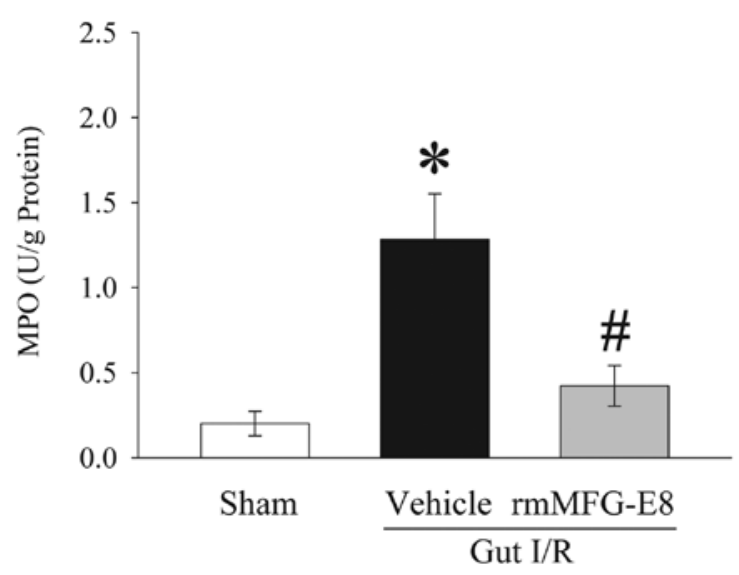

Figure 5. Inhibition of intestinal neutrophil infiltration by rmMFG-E8 after gut I/R. Neutrophil activity was assessed by MPO assay in sham-operated animals (Sham) and ischemia/reperfusion animals treated with normal saline (Vehicle) or rmMFG-E8 at $4 \mathrm{~h}$ after reperfusion. Data are expressed as means $\pm \mathrm{SE},{ }^{*} \mathrm{P}<0.05$ vs. Sham, ${ }^{\text {"}} \mathrm{P}<0.05$ vs. Vehicle by one-way ANOVA and Student Newman-Keuls test, $n=6 /$ group.

tissue by TUNEL staining (Fig. 3). Treatment with rmMFG$\mathrm{E} 8$, however, suppressed the number of detectable apoptotic cells in the small intestine after gut I/R injury.

rmMFG-E8 mitigates intestinal injury after gut I/R. Mucosal destruction, loss of villi and epithelial cells, hemorrhage, and infiltration of inflammatory cells were observed microscopically in the rat intestine after I/R as compared with sham controls (Fig. 4). Treatment with rmMFG-E8 dramatically improved these microscopic alterations. The level of MPO activity is an indicator of neutrophil infiltration. As demonstrated in Fig. 5, gut I/R induced a more than 5-fold increase in intestinal MPO activities in vehicle-treated rats as compared with sham animals. Treatment with rmMFG-E8 significantly inhibited the increase in intestinal MPO activities by $67 \%$ after gut $\mathrm{I} / \mathrm{R}(\mathrm{P}<0.05)$. 


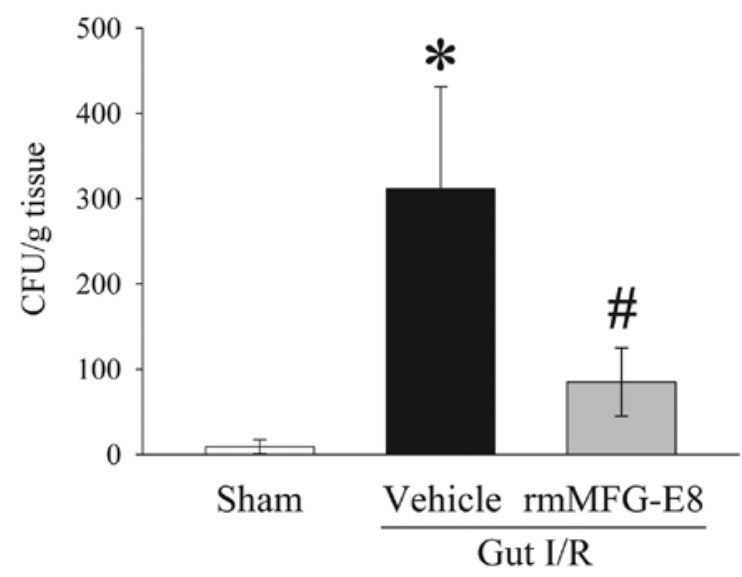

Figure 6. Suppression of bacterial translocation to mesenteric lymph nodes (MLN) by rmMFG-E8 after gut I/R. Bacterial translocation to mesenteric lymph nodes in sham-operated animals (Sham) and ischemia/reperfusion animals treated with normal saline (Vehicle) or rmMFG-E8 at $4 \mathrm{~h}$ after reperfusion. Data are presented as means $\pm S E(n=6)$, and compared by one-way ANOVA and Student Newman-Keuls test: "P<0.05 vs. Sham group;

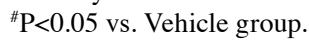

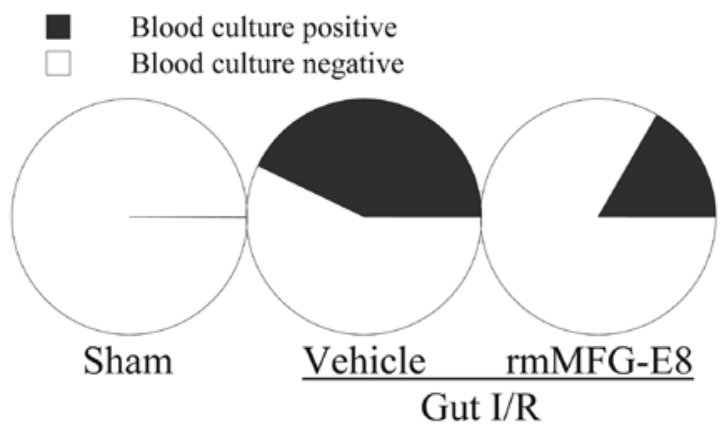

Figure 7. Reduction of bacteremia by rmMFG-E8 after gut I/R. Bacteremia was determined by blood culture in sham-operated animals $(\mathrm{Sham}, \mathrm{n}=6)$ and ischemia/reperfusion animals treated with normal saline (Vehicle, $n=7$ ) or rmMFG-E8 $(n=6)$ at $4 \mathrm{~h}$ after reperfusion.

rmMFG-E8 reduces bacterial translocation after gut $I / R$. Bacterial translocation to the MLN was minimal in the sham group, but was extensive in the gut $\mathrm{I} / \mathrm{R}$ vehicle-treated group $(\mathrm{P}<0.05)$ (Fig. 6). Treatment with rmMFG-E8 at the time of reperfusion, however, significantly ameliorated the development of bacterial translocation. Moreover, bacteremia was determined by blood culture. As shown in Fig. 7, 3 of 7 vehicle-treated gut I/R animals developed bacteremia at $4 \mathrm{~h}$ post reperfusion. However, only 1 of 6 rmMFG-E8-treated gut $\mathrm{I} / \mathrm{R}$ animals showed a positive blood culture result.

rmMFG-E8 increases intestinal VEGF expression after gut $I / R$. Intestinal levels of VEGF decreased by $63 \%$ at $4 \mathrm{~h}$ after gut I/R. Administration of rmMFG-E8 at the time of reperfusion, however, significantly increased VEGF expression in the gut by $123 \%$ at $4 \mathrm{~h}$ after reperfusion $(\mathrm{P}<0.05)$ (Fig. 8$)$.

\section{Discussion}

Gut $\mathrm{I} / \mathrm{R}$ injury is a serious condition in the intensive care units and among vascular surgical patients. A key aspect of

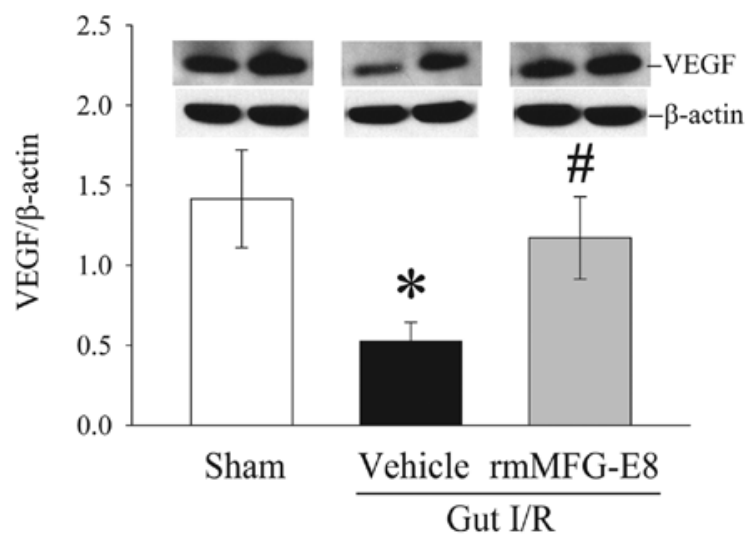

Figure 8. Upregulation of VEGF by rmMFG-E8 after gut I/R. VEGF protein levels in the small intestine were measured by western blot analysis in sham-operated animals (Sham) and ischemia/reperfusion animals treated with normal saline (Vehicle) or rmMFG-E8 at $4 \mathrm{~h}$ after reperfusion. Data are presented as means $\pm \operatorname{SE}(n=4)$, and compared by one-way ANOVA and Student Newman-Keuls test: ${ }^{~} \mathrm{P}<0.05$ vs. Sham group; ${ }^{\mathrm{P}} \mathrm{P}<0.05$ vs. Vehicle group.

I/R injury is the increased occurrence of apoptotic cell death in the gut (7-9). In the current study, we found that intestinal levels of MFG-E8 are significantly reduced after I/R injury, which correlates with increased apoptosis and impaired barrier function. MFG-E8 is a glycoprotein secreted from the glandular epithelial cells in milk fat globules during lactation (25-27). In milk, MFG-E8 acts as an antiviral protein, inhibiting the symptoms of rotavirus infection (28). Recent studies have shown that MFG-E8 is also produced by macrophages and dendritic cells and has been linked to the opsonization of apoptotic cells $(20,21,29-31)$. It plays a crucial role in the clearance of apoptotic cells (19-21). Binding of MFG-E8 to phosphatidylserine (PS) exposed on the surface of apoptotic cells opsonizes them for a complete engulfment by macrophages via $\alpha_{v} \beta_{3}$ - or $\alpha_{v} \beta_{5}$-integrins (32). Without MFG-E8, full engulfment and the removal of apoptotic cells cannot be completed (21). In this regard, gut I/R induces apoptosis in the small intestine, and decreases apoptotic cell clearance through the downregulation of MFG-E8 at the same time. The reduced levels of MFG-E8 in the small intestine after I/R injury may contribute to the increased apoptosis under such a condition.

The current study also shows that administration of rmMFG-E8 decreases apoptosis, mitigates bacterial translocation, inhibits neutrophil infiltration, and promotes tissue repair after gut I/R. The most noteworthy function of MFG-E8 is its ability to promote the clearance of apoptotic cells by forming a tether between phagocytes and apoptotic cells. Excessive apoptosis has various pathological consequences. Recent studies have shown that the lack of clearance of apoptotic cells in the spleen potentially leads to autoimmune diseases $(20,21)$. Accumulated apoptotic cells may undergo secondary necrosis. These cells leak their dangerous contents such as cytokines and enzymes, therefore, exaggerating inflammation and potentiating tissue injury under such conditions. Administration of rmMFG-E8 enhances apoptotic cell clearance, and therefore, a secondary (post-apoptotic) necrosis of apoptotic cells is prevented. Hence, the potential harm from apoptotic cells by leakage of their dangerous contents due to secondary necrosis is abrogated. 
Organ injury induced by $\mathrm{I} / \mathrm{R}$ is not necessarily limited to the ischemic organ. The clinical features of gut ischemia originate from both local and systemic responses. Gut I/R injury i s one of the most common causes of gut barrier disruption (33). Loss of the barrier function of the gastrointestinal tract has been implicated as a potential source of multiple organ failure under such a condition. The gastrointestinal tract not only functions as a site for nutrient absorption but also acts as a barrier between the circulation and noxious substances such as intraluminal organisms entering the circulation (34). Maintenance of normal epithelial structure and function is important in preventing transcellular and paracellular movement of large molecules and bacteria (35). Increased intestinal permeability has been reported to be associated with an increased risk of complications, multiple organ failure, or even mortality in critically ill patients (36-38). Our previous study has shown that the administration of rmMFG-E8 attenuates lung injury after gut I/R (24). In this regard, the restoration of gut barrier function by rmMFG-E8 treatment may also contribute to attenuated lung injury under certain conditions.

MFG-E8 appears to play an important role in the maintenance of intestinal homeostasis and the promotion of mucosal healing. In breast milk fed infants, MFG-E8 is involved in the uptake of milk fat globules in the gut (25-27). It is also an important milk mucin-associated defense component that inhibits enteric pathogen binding and infectivity (39). Previous studies have shown that MFG-E8 regulates the migration of enterocytes and intestinal repair (40) and plays a role in VEGF-dependent neovascularization (41). Various studies have demonstrated that VEGF promotes angiogenesis during acute inflammation and ischemia $(42,43)$. VEGF also plays a role in counteracting the local imbalance of fibrogenesis and fibrolysis, leading to an accumulation of immature subepithelial matrix in collagenous colitis (44). Using intravital microscopy of the rat mesenteric microcirculation to measure leukocyte-endothelium interactions, Scalia et al (45) demonstrated that VEGF inhibits leukocyte-epithelial cell adherence and the effects of chronic inflammation. In the current study, we found that MFG-E8 treated animals had higher levels of VEGF in the small intestine after I/R injury. Therefore, increasing VEGF production may be a novel mechanism for MFG-E8-promoted mucosal healing after I/R injury.

In summary, using an established animal model of gut I/R such as a superior mesenteric artery occlusion, we showed that intestinal levels of MFG-E8 are significantly reduced after I/R injury, which correlated with increased apoptosis and impaired barrier function. In addition, administration of rmMFG-E8, decreases apoptosis, mitigates bacterial translocation, inhibits neutrophil infiltration, and promotes tissue repair after gut I/R. Thus, enhancing apoptotic cell clearance by rmMFG-E8 can be a novel concept in the treatment of gut I/R injury.

\section{Acknowledgements}

This study was supported by the National Institutes of Health grants R01 GM053008, R01 AG028352 and R01 GM057468 (P.W.).

\section{References}

1. Oldenburg WA, Lau LL, Rodenberg TJ, Edmonds HJ and Burger CD: Acute mesenteric ischemia: a clinical review. Arch Intern Med 164: 1054-1062, 2004.

2. Berlanga J, Prats P, Remirez D, Gonzalez R, Lopez-Saura P, Aguiar J, Ojeda M, Boyle JJ, Fitzgerald AJ and Playford RJ: Prophylactic use of epidermal growth factor reduces ischemia/ reperfusion intestinal damage. Am J Pathol 161: 373-379, 2002.

3. Brandt LJ and Boley SJ: AGA technical review on intestinal ischemia. American Gastrointestinal Association. Gastroenterology 118: 954-968, 2000.

4. Rocourt DV, Mehta VB and Besner GE: Heparin-binding EGF-like growth factor decreases inflammatory cytokine expression after intestinal ischemia/reperfusion injury. J Surg Res 139: 269-273, 2007.

5. Hassoun HT, Kone BC, Mercer DW, Moody FG, Weisbrodt NW and Moore FA: Post-injury multiple organ failure: the role of the gut. Shock 15: 1-10, 2001.

6. Fink MP: Effect of critical illness on microbial translocation and gastrointestinal mucosa permeability. Semin Respir Infect 9: 256-260, 1994

7. Matthijsen RA, Derikx JP, Kuipers D, van Dam RM, Dejong CH and Buurman WA: Enterocyte shedding and epithelial lining repair following ischemia of the human small intestine attenuate inflammation. PLoS ONE 4: e7045, 2009.

8. Huang CY, Hsiao JK, Lu YZ, Lee TC and Yu LC: Anti-apoptotic PI3K/Akt signaling by sodium/glucose transporter 1 reduces epithelial barrier damage and bacterial translocation in intestinal ischemia. Lab Invest 91: 294-309, 2011.

9. Di PR, Esposito E, Mazzon E, Paterniti I, Galuppo M and Cuzzocrea S: GW0742, a selective PPAR-beta/delta agonist, contributes to the resolution of inflammation after gut ischemia/ reperfusion injury. J Leukoc Biol 88: 291-301, 2010.

10. Oberholzer A, Oberholzer C, Minter RM and Moldawer LL: Considering immunomodulatory therapies in the septic patient: should apoptosis be a potential therapeutic target? Immunol Lett 75: 221-224, 2001

11. Efron PA, Tinsley K, Minnich DJ, Monterroso V, Wagner J, Lainee P, Lorre K, Swanson PE, Hotchkiss R and Moldawer LL: Increased lymphoid tissue apoptosis in baboons with bacteremic shock. Shock 21: 566-571, 2004.

12. Hotchkiss RS, Swanson PE, Freeman BD, Tinsley KW, Cobb JP, Matuschak GM, Buchman TG and Karl IE: Apoptotic cell death in patients with sepsis, shock, and multiple organ dysfunction. Crit Care Med 27: 1230-1251, 1999.

13. Hotchkiss RS, Coopersmith CM and Karl IE: Prevention of lymphocyte apoptosis - a potential treatment of sepsis? Clin Infect Dis 41 (Suppl 7): S465-S469, 2005.

14. Hotchkiss RS, Osmon SB, Chang KC, Wagner TH, Coopersmith CM and Karl IE: Accelerated lymphocyte death in sepsis occurs by both the death receptor and mitochondrial pathways. J Immunol 174: 5110-5118, 2005.

15. Mahidhara R and Billiar TR: Apoptosis in sepsis. Crit Care Med 28: N105-N113, 2000

16. Ayala A, Xin XY, Ayala CA, Sonefeld DE, Karr SM, Evans TA and Chaudry IH: Increased mucosal B-lymphocyte apoptosis during polymicrobial sepsis is a Fas ligand but not an endotoxinmediated process. Blood 91: 1362-1372, 1998.

17. Wesche DE, Lomas-Neira JL, Perl M, Chung CS and Ayala A: Leukocyte apoptosis and its significance in sepsis and shock. J Leukoc Biol 78: 325-337, 2005.

18. Wesche-Soldato DE, Chung CS, Lomas-Neira J, Doughty LA, Gregory SH and Ayala A: In vivo delivery of caspase-8 or Fas siRNA improves the survival of septic mice. Blood 106: 2295-2301, 2005.

19. Hanayama R, Miyasaka K, Nakaya M and Nagata S: MFG-E8dependent clearance of apoptotic cells, and autoimmunity caused by its failure. Curr Dir Autoimmun 9: 162-172, 2006.

20. Hanayama R, Tanaka M, Miwa K, Shinohara A, Iwamatsu A and Nagata S: Identification of a factor that links apoptotic cells to phagocytes. Nature 417: 182-187, 2002.

21. Hanayama R, Tanaka M, Miyasaka K, Aozasa K, Koike M, Uchiyama $Y$ and Nagata S: Autoimmune disease and impaired uptake of apoptotic cells in MFG-E8-deficient mice. Science 304: 1147-1150, 2004. 
22. Miksa M, Wu R, Dong W, Das P, Yang D and Wang P: Dendritic cell-derived exosomes containing milk fat globule epidermal growth factor-factor VIII attenuate proinflammatory responses in sepsis. Shock 25: 586-593, 2006.

23. Miksa M, Wu R, Dong W, Komura H, Amin D, Ji Y, Wang Z, Wang H, Ravikumar TS, Tracey KJ and Wang P: Immature dendritic cell-derived exosomes rescue septic animals via milk fat globule epidermal growth factor VIII. J Immunol 183: 5983-5990, 2009.

24. Cui T, Miksa M, Wu R, Komura H, Zhou M, Dong W, Wang Z, Higuchi S, Chaung W, Blau SA, et al: Milk fat globule epidermal growth factor 8 attenuates acute lung injury in mice after intestinal ischemia and reperfusion. Am J Respir Crit Care Med 181: 238-246, 2010 .

25. Akakura S, Singh S, Spataro M, Akakura R, Kim JI, Albert ML and Birge RB: The opsonin MFG-E8 is a ligand for the alphavbeta5 integrin and triggers DOCK180-dependent Rac1 activation for the phagocy tosis of apoptotic cells. Exp Cell Res 292: 403-416, 2004.

26. Oshima K, Aoki N, Negi M, Kishi M, Kitajima K and Matsuda T: Lactation-dependent expression of an mRNA splice variant with an exon for a multiply O-glycosylated domain of mouse milk fat globule glycoprotein MFG-E8. Biochem Biophys Res Commun 254: 522-528, 1999.

27. Taylor MR, Couto JR, Scallan CD, Ceriani RL and Peterson JA Lactadherin (formerly BA46), a membrane-associated glycoprotein expressed in human milk and breast carcinomas, promotes Arg-Gly-Asp (RGD)-dependent cell adhesion. DNA Cell Biol 16: 861-869, 1997.

28. Newburg DS, Peterson JA, Ruiz-Palacios GM, Matson DO, Morrow AL, Shults J, Guerrero ML, Chaturvedi P, Newburg SO, Scallan CD, et al: Role of human-milk lactadherin in protection against symptomatic rotavirus infection. Lancet 351: 1160-1164, 1998.

29. Miyasaka K, Hanayama R, Tanaka M and Nagata S: Expression of milk fat globule epidermal growth factor 8 in immature dendritic cells for engulfment of apoptotic cells. Eur J Immunol 34: 1414-1422, 2004.

30. Thery C, Regnault A, Garin J, Wolfers J, Zitvogel L, RicciardiCastagnoli P, Raposo G and Amigorena S: Molecular characterization of dendritic cell-derived exosomes. Selective accumulation of the heat shock protein hsc73. J Cell Biol 147: 599-610, 1999

31. Oshima K, Aoki N, Kato T, Kitajima K and Matsuda T: Secretion of a peripheral membrane protein, MFG-E8, as a complex with membrane vesicles. Eur J Biochem 269: 1209-1218, 2002.

32. Veron P, Segura E, Sugano G, Amigorena S and Thery C: Accumulation of MFG-E8/lactadherin on exosomes from immature dendritic cells. Blood Cells Mol Dis 35: 81-88, 2005.

33. Swank GM and Deitch EA: Role of the gut in multiple organ failure: bacterial translocation and permeability changes. World J Surg 20: 411-417, 1996.
34. Souba WW, Smith RJ and Wilmore DW: Glutamine metabolism by the intestinal tract. JPEN J Parenter Enteral Nutr 9: 608-617, 1985.

35. Marin ML, Greenstein AJ, Geller SA, Gordon RE and Aufses AH Jr: A freeze fracture study of Crohn's disease of the terminal ileum: changes in epithelial tight junction organization. Am J Gastroenterol 78: 537-547, 1983.

36. Ammori BJ, Leeder PC, King RF, Barclay GR, Martin IG, Larvin $\mathrm{M}$ and McMahon MJ: Early increase in intestinal permeability in patients with severe acute pancreatitis: correlation with endotoxemia, organ failure, and mortality. J Gastrointest Surg 3: 252-262, 1999.

37. Faries PL, Simon RJ, Martella AT, Lee MJ and Machiedo GW: Intestinal permeability correlates with severity of injury in trauma patients. J Trauma 44: 1031-1035, 1998

38. Doig CJ, Sutherland LR, Sandham JD, Fick GH, Verhoef M and Meddings JB: Increased intestinal permeability is associated with the development of multiple organ dysfunction syndrome in critically ill ICU patients. Am J Respir Crit Care Med 158: 444-451, 1998.

39. Yolken RH, Peterson JA, Vonderfecht SL, Fouts ET, Midthun K and Newburg DS: Human milk mucin inhibits rotavirus replication and prevents experimental gastroenteritis. J Clin Invest 90: 1984-1991, 1992.

40. Bu HF,Zuo XL, Wang X, Ensslin MA, Koti V, Hsueh W, Raymond AS, Shur BD and Tan XD: Milk fat globule-EGF factor 8/lactadherin plays a crucial role in maintenance and repair of murine intestinal epithelium. J Clin Invest 117: 3673-3683, 2007.

41. Silvestre JS, Thery C, Hamard G,Boddaert J,Aguilar B, Delcayre A, Houbron C, Tamarat R, Blanc-Brude O, Heeneman S, et al: Lactadherin promotes VEGF-dependent neovascularization. Nat Med 11: 499-506, 2005.

42. Wang Y, Haider HK, Ahmad N, Xu M, Ge R and Ashraf M: Combining pharmacological mobilization with intramyocardial delivery of bone marrow cells over-expressing VEGF is more effective for cardiac repair. J Mol Cell Cardiol 40: 736-745, 2006.

43. Von DE, Meyer S, Thorn D, Marme D, Hopt UT and Thomusch O: Targeting vascular endothelial growth factor pathway offers new possibilities to counteract microvascular disturbances during ischemia/reperfusion of the pancreas. Transplantation 82: 543-549, 2006.

44. Griga T, Tromm A, Schmiegel W, Pfisterer O, Muller KM and Brasch F: Collagenous colitis: implications for the role of vascular endothelial growth factor in repair mechanisms. Eur J Gastroenterol Hepatol 16: 397-402, 2004.

45. Scalia R, Booth G and Lefer DJ: Vascular endothelial growth factor attenuates leukocyte-endothelium interaction during acute endothelial dysfunction: essential role of endothelium-derived nitric oxide. FASEB J 13: 1039-1046, 1999. 